\title{
Pterygium and associated factors among adults: a hospital-based prospective study
}

\author{
Chhimi Wangmo ${ }^{1}$, Nor T. Lepcha ${ }^{2}$ \\ ${ }^{1}$ Khesar Gyalpo University of Medical Sciences of Bhutan, Thimphu, Bhutan \\ ${ }^{2}$ Jigme Dorji Wangchuck National Referral Hospital, Thimphu, Bhutan
}

\begin{abstract}
Purpose: The aim of this hospital-based study was to assess the prevalence and associated factors of pterygium among adult patients visiting the Ophthalmology Outpatient Department (OPD) in the Jigme Dorji Wangchuck National Referral Hospital (JDWNRH), Thimphu. Methods: A cross sectional study was carried out in the ophthalmology OPD in the national referral hospital, Thimphu from $1^{\text {st }}$ January, 2018 to $31^{\text {st }}$ December, 2018, during which 1599 adult patients were selected through systematic random sampling. Results: The prevalence of pterygium was $12.8 \%$ (95\% CI: $11.2-14.5$ ). Among 271 eyes with pterygium, the distribution of grade 1, grade 2 and grade 3 pterygium was $34.7 \%, 56.1 \%$ and $9.2 \%$ respectively. Pterygium was most common in the age group of 36-55 years. The significant factors associated with pterygium were age group, occupation and usage of sunglasses. Individuals who were 36-55 years (adjusted OR 2.70, 95\% CI 1.82-4.0) and $>55$ years (adjusted OR 2.17, $95 \%$ CI 1.34-3.50) had significantly higher risk than 18-35 years $(p<0.002)$, and not using sunglasses (adjusted OR $1.97,95 \%$ CI $1.17-3.33, p=0.007$ ) significantly increased the risk of pterygium. Indoor occupation, particularly being a student was protective against pterygium (OR $0.08,95 \%$ CI 10.02-0.33, $p<0.001$ ). Only $14.1 \%$ used sunglasses and among them, $27.6 \%$ were aware that sunglasses can protect from ultraviolet radiation. Conclusions: This study found a high prevalence of pterygium among adults aged 18 years and above. Those aged 36-55 years and an occupation involving outdoor activities were affected more. Encouraging usage of sunglasses may reduce pterygium.
\end{abstract}

Keywords: Associated factors; Hospital-based; Prevalence; Pterygium.

\section{INTRODUCTION}

Pterygium (Greek: pterygos, meaning "wing") is a triangular fibrovascular subepithelial ingrowth of degenerative bulbar conjunctival tissue over the limbus onto the cornea ${ }^{1}$. Pterygium is one of the most common chronic eye diseases. The reported global prevalence ranges from $0.74 \%$ to $39.6 \%$, depending on the population studied ${ }^{2,3}$. A meta-analysis of 20 studies reported a pooled prevalence rate of pterygium of $10.2 \%$ in the general population ${ }^{4}$. Several population-based studies have shown that the prevalence of pterygium varied with age, gender, occupation and the place of residence $e^{3-7}$.

The exact etiology of pterygium is unknown; however, a strong positive correlation has been found with increased cumulative exposure to ultraviolet (UV) radiation ${ }^{8}$. Numerous studies have found an increased prevalence of pterygium in Asia and other countries in the "pterygium belt" located between $37^{\circ}$ north and the south of the equator ${ }^{7,9,10}$. A study conducted in Australia reported a significant association between pterygium

\footnotetext{
Corresponding author:

Chhimi Wangmo

chimizumc@gmail.com
}

and increased skin and hair pigmentation and sun related damage ${ }^{11}$. Pterygium is associated with older age, outdoor occupation, male gender and low educational level $1^{4-7,10,12}$.

Pterygium can cause significant ocular surface irritation and tear film disturbances ${ }^{13}$. It can also result in corneal irregularity, inducing significant amount of astigmatism ${ }^{14,15}$. If pterygium is left untreated and protective measures are not taken, fibrovascular growth of conjunctiva over the visual axis can impair vision ${ }^{15}$.

The specific objectives of the study are to describe the socio-demographic profile of adult patients presenting with pterygium to the Ophthalmology Out Patient Department at JDWNRH Hospital and to assess awareness of use of sunglasses to prevent pterygium.

\section{METHODS}

This hospital-based cross-sectional study was conducted on patients presenting to the Ophthalmology OPD at the National Referral Hospital in Thimphu for a period of one year from $1^{\text {st }}$ January, 2018 to $31^{\text {st }}$ December, 2018. The study was conducted in accordance with the tenets of the Declaration of Helsinki and the study protocol was approved by the Research Ethics Board 
of Health, Ministry of Health vide approval letter No. REBH/ Approval/2017/069.

Systematic random sampling technique was used to recruit the participants. The OPD sees an average of $100(\mathrm{~N})$ patients in a day. With the aim to interview up to $10(\mathrm{~N})$ participants a day, every tenth patient was selected and interviewed. The OPD reception desk issued a serial number to each patient. Every day, the first patient was randomly selected by generating a random number. A random number from one to ten was generated using a random number generator application. Thereafter, every tenth patient was selected until the last tenth patient in a day. If the selected patient falls within the exclusion criteria, then the next tenth patient was interviewed. Patients below the age of 18 years, old cases of pterygium and those who refused to consent were excluded from the study.

\section{Data collection}

Data was obtained by administering a pre-tested and wellstructured questionnaire, administered by a Resident or Consultant Ophthalmologist. Age was categorized into three categories based on likelihood of current ocular sun exposure, young adults (aged 18-35 years), middle-aged adults (aged 36-55 years), and older adults (aged 56 years and above) ${ }^{16}$. Following the interview, participants were subjected to ophthalmic examination which included measurement of visual acuity, refraction and slitlamp bio-microscopy examination.

\section{Definition of pterygium}

The grading of pterygium was based on the extent of corneal involvement by the apex of the pterygium ${ }^{17}$. The size of pterygium (distance in millimeters from the limbus to the apex of the lesion on the cornea) was measured using the slit beam of the slit lamp biomicroscope.

- Grade one: Apex of triangular fibrovascular growth of conjunctiva crossing limbus but less than $2 \mathrm{~mm}$ onto the cornea.

- Grade two: Apex of triangular fibrovascular growth of conjunctiva extends up to $4 \mathrm{~mm}$ of cornea

- Grade three: Apex of triangular fibrovascular growth of conjunctiva encroaches onto more than $4 \mathrm{~mm}$ of cornea and involves the visual axis.

\section{Statistical analysis}

Data was entered into and managed using EpiData version 3.1. Descriptive data was analyzed using EpiData Analysis version 2.2.2.183. Statistical analysis was done utilizing the Statistical Package for Social Sciences (IBM SPSS version 21)

\section{RESULTS}

Of the 1625 adults that were selected through the sampling process, 1599 (98.4\%) participated in the study. Among the participants, $56.9 \%$ were female and $43.1 \%$ were male. Majority

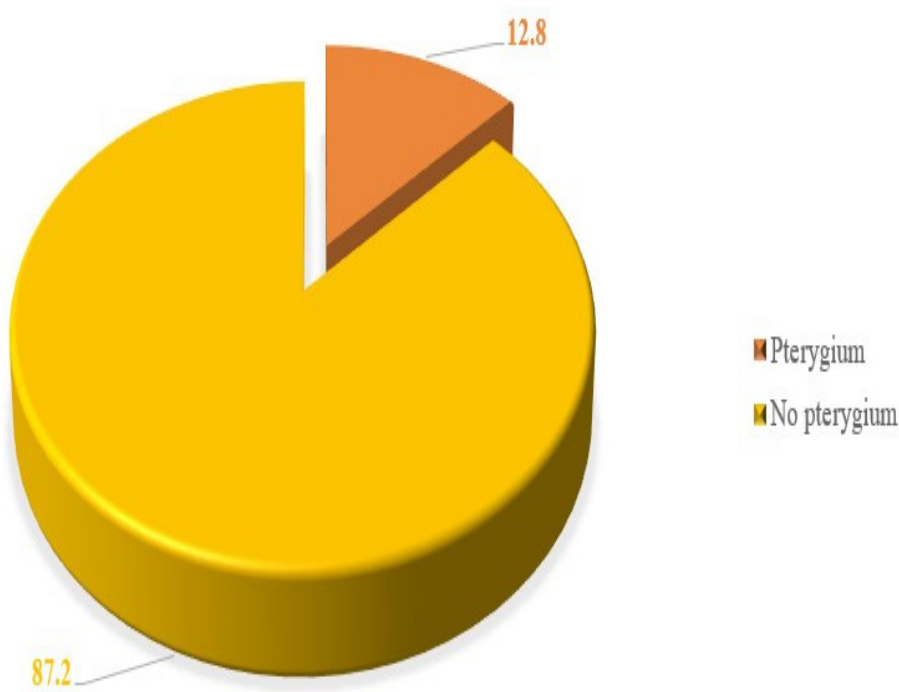

Figure 1. Prevalence of pterygium among adult patients $(n=1599)$ presenting to Ophthalmology outpatient department of the National Referral Hospital, Thimphu during the period January 1, 2018 to December 31, 2018

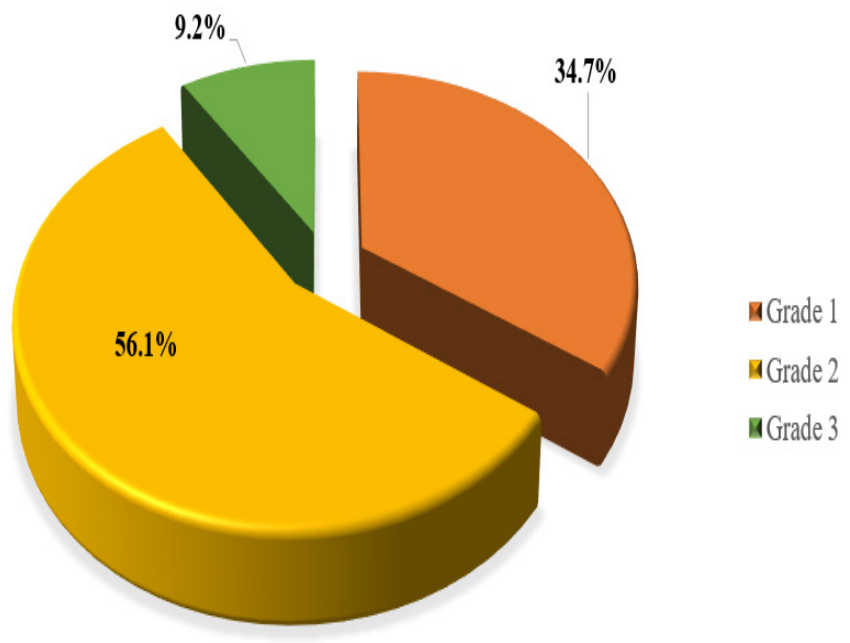

Figure 2. Distribution of grades of pterygium by eyes involved $(n=271)$ among patients presenting to Ophthalmology outpatient department of the National Referral Hospital, Thimphu during the period January 1, 2018 to December 31, 2018

of participants belonged to $18-35$ years age group (46.2\%). Of 1599 adults, 204 individuals had pterygium, so the prevalence of pterygium among patients aged 18 years and above was $12.8 \%$ (Figure 1).

The distribution of pterygium according to sociodemographic variables is as shown in Table 1.

Among 204 participants with pterygium, 87 (42.6\%) were involving the right eye, $50(24.5 \%)$ involved the left eye and $67(32.8 \%)$ involved both the eyes. The distribution of grade of pterygium by eyes involved among the study group is depicted in Figure 2. 
Table 1. Distribution of pterygium according to socio-demographic variables in patients presenting to Ophthalmology Outpatient Department of the National Referral Hospital, Thimphu, Bhutan during the period January 1 , 2018 to December 31, 2018

\section{Socio demographic variables}

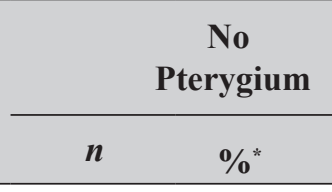

56 and above

Sex

Female

Male

\section{Education level}

No schooling

Non-formal education

Primary/lower secondary

Higher secondary

Diploma

Degree or higher

Monastic

\section{Occupation}

Farmer

Housewives/Househusband

Office goers

Military

Student

Monastics

Construction/Industrial Workers

Others

\section{Use of sunglasses}

No

Total (n)

Yes

No

\footnotetext{
${ }^{*}$ Column percentages presented
}

100

$\begin{array}{llcccc}870 & 62.4 & 116 & 56.9 & 986 & 61.7 \\ 525 & 37.6 & 88 & 43.1 & 613 & 38.3\end{array}$

694

441

260

\section{Pterygium}

49.7

44

105

55

18.6

506

36.3

38

2.7

187

13.4

408

29.2

53

3.8

164

11.8

39

$$
2.8
$$

296

21.2

23.6

329

310

22.2

25

1.8

237

17.0

51

3.7

46

101

$$
3.3
$$

7.2

206

14.8

1189

85.2

1395
94

7

29

46.1

13.4

14.2

22.1

2.9

10.3

1.0

34.3

22.5

23.0

3.9

1.0

0.5

3.9

10.8

9.3

90.7

185

204
Total

n

738

46.2

34.1

19.7

315

600

37.5

2.8

13.5

28.3

3.7

11.6

2.6

41

22.9

23.5

22.3

2.1

14.9

3.3

3.4

7.7

123

225

14.1

85.9

100 
Table 2. Results of unconditional association and multivariable binary logistic regression assessing the risk factors for pterygium in adult patients presenting to Ophthalmology Outpatient Department of the National Referral Hospital, Thimphu, Bhutan during the period January 01, 2018 to December 31, 2018

\begin{tabular}{|c|c|c|c|c|c|}
\hline Variable & & $\begin{array}{c}\text { Unadjusted OR } \\
(95 \%)\end{array}$ & $\begin{array}{c}\text { Unadjusted } \mathrm{OR} \\
p \text { value }\end{array}$ & $\begin{array}{c}\text { Adjusted OR } \\
(95 \% \mathrm{CI})\end{array}$ & $\begin{array}{c}\text { Adjusted } O R \\
p \text { value }\end{array}$ \\
\hline Age & & & Overall $<0.001$ & & Overall $<0.001$ \\
\hline 18-35 years & & Baseline & - & Baseline & \\
\hline $36-55$ years & & $3.76(2.59-5.45)$ & $<0.001$ & $2.70(1.82-4.0)$ & $<0.001$ \\
\hline$>55$ years & & $3.34(2.19-5.08)$ & $<0.001$ & $2.17(1.34-3.50)$ & 0.002 \\
\hline Occupation & & & Overall $<0.001$ & & Overall $<0.001$ \\
\hline Farmer & & Baseline & Baseline & - & Baseline \\
\hline Housewife & & $0.59(0.40-0.89)$ & $0.64(0.42-0.98)$ & $0.64(0.42-0.98)$ & 0.038 \\
\hline Office goer & & $0.64(0.43-0.96)$ & $0.91(0.58-1.44)$ & $0.91(0.58-1.44)$ & 0.700 \\
\hline Military & & $1.35(0.59-3.13)$ & $1.58(0.67-3.75)$ & $1.58(0.67-3.75)$ & 0.299 \\
\hline Student & & $0.04(0.01-0.15)$ & $0.08(0.02-0.33)$ & $0.08(0.02-0.33)$ & 0.001 \\
\hline Monastic & & $0.08(0.01-0.61)$ & $0.10(0.01-0.77)$ & $0.10(0.01-0.77)$ & 0.027 \\
\hline Construction worker & & $0.74(0.33-1.63)$ & $1.01(0.44-2.30)$ & $1.01(0.44-2.30)$ & 0.984 \\
\hline Others & & $0.92(0.54-1.56)$ & $1.49(0.83-2.66)$ & $1.49(0.83-2.66)$ & 0.174 \\
\hline Sunglass usage & & & Overall $=\mathbf{0 . 0 2 9}$ & & Overall $=\mathbf{0 . 0 0 7}$ \\
\hline & Yes & Baseline & Baseline & Baseline & - \\
\hline & No & $1.69(1.03-2.77)$ & $1.97(1.17-3.33)$ & $1.97(1.17-3.33)$ & 0.011 \\
\hline Constant/Intercept & & - & & $0.06(0.03-0.11)$ & $<0.001$ \\
\hline $\operatorname{Sex}^{*}$ & & & Overall $=\mathbf{0 . 1 3 3}$ & \multicolumn{2}{|c|}{ Not significant $(p$-value $=0.785)$} \\
\hline Female & & Baseline & - & & \\
\hline Male & & $1.26(0.09-1.69)$ & 0.132 & & \\
\hline Education level $^{*}$ & & & Overall $=0.067$ & \multicolumn{2}{|c|}{ Not significant $(p$-value $=0.209)$} \\
\hline No schooling & & Baseline & - & & \\
\hline Non-formal & & $0.99(0.43-2.29)$ & 0.984 & & \\
\hline Lower secondary & & $0.84(0.53-1.31)$ & 0.43 & & \\
\hline Higher secondary & & $0.59(0.41-0.87)$ & 0.007 & & \\
\hline Diploma & & $0.61(0.26-1.46)$ & 0.266 & & \\
\hline Degree & & $0.69(0.42-1.14)$ & 0.149 & & \\
\hline Monastic & & $0.28(0.07-1.16)$ & 0.079 & & \\
\hline
\end{tabular}

"These variables are not significant in multivariable model

Majority of pterygium patients had ocular surface irritation 135 (66.2\%) as the predominant symptom. Of the 1599 individuals, only 225 (14.1\%) participants ever used sunglasses. The association between pterygium and socio-demographic variables are shown in Table 2.

\section{DISCUSSION}

The prevalence of pterygium among adults aged 18 years and above visiting the Ophthalmology OPD of JDWNRH was 12.8\% (95\% CI:11.2-14.5). Among 271 eyes with pterygium, 
the distribution of grade 1 , grade 2 and grade 3 pterygium was $34.7 \%, 56.1 \%$ and $9.2 \%$ respectively. A study among residents of Gondar city, South - East Ethiopia, aged 20 years and above reported $38.7 \%$ prevalence of pterygium, comparatively higher than what was observed in our study. A study by Shrestha et al among those 20 years and above residing in Kathmandu, Nepal observed a prevalence of $12.4 \%$, which was in line with our study finding. This compatible finding could be due to similar geographic location and socioeconomic status of the population studied. A low prevalence of $2.8 \%$ was observed in Victoria in Australia $^{18}$. The marked discrepancies in the reported prevalence of pterygium across countries might be due to differences in population studied in different regions of the world, variations in geographic and climatic settings, lifestyle and living conditions and awareness leading to differential exposure to ultraviolet radiation. There is an independent association between pterygium and outdoor occupation.

Prevalence of pterygium increased with age, reached a peak and then declined. This could be possible due to decrease in total number of fibroblast and fibroblast proliferative activity with age. Fibroblasts are required for proliferation of fibrovascular tissue and pterygium progression.

Although the participants' sunglass usage with every occasion of sunlight exposure or the exact hour of sunglass wear could not be assessed, a crude measurement of sunglass use has shown that the use of sunglasses is protective against pterygium. The risk of developing pterygium among those who did not use sunglasses was significantly higher than those who did, even when adjusted for age and occupation $(p<0.001)$. Similar to our study, the Barbados Eye Study and the study among the motorcyclists in Nigeria found that the use of sunglasses reduced the risk of developing pterygium, probably by absorbing and reducing the exposure to harmful ultraviolet radiations ${ }^{19,22^{\circ}}$. Our study also found a significant linear correlation between sunglass use and educational qualification, with the highest sunglass users being among the educated lot $(p=0.007)$.

While most studies reported an increased prevalence of pterygium among men compared with women, our study did not find a significant association between gender and pterygium ${ }^{6-\gamma}$. In line with the current finding, the Andhra Pradesh Eye Disease study also demonstrated a similar prevalence in male and female ${ }^{12}$. In contrast, a study in Tibet reported that women were at higher risk of developing pterygium then men, which seemed to be associated with their life-style ${ }^{21}$. It was attributed to more hours of sunlight exposure as women in Tibet are more often involved in outdoor activities.

Our study did not find any significant association between pterygium and educational qualification, which was in line with several other studies ${ }^{22-24}$. There are however, some studies that have reported the prevalence of pterygium as highest amongst illiterate participants, attributing it to the differences in occupational conditions and lifestyle between the educated and the uneducated or lesser educated people ${ }^{6-8}$.
The causal relationship of pterygium and sunglasses could not be determined as it was difficult to establish temporal precedence of initiation of sunglass use and development of pterygium.

The predictive ability of the model was low with pseudo- $\mathrm{R}^{2}$ value of $9 \%$, and this was because only three variables have been found significant. This indicated there could be many other risk factors for pterygium that were not captured in our study. Future studies should explore considering more accurate measurement of outdoor activities, genetic characteristics and allergy history among others.

\section{CONCLUSIONS}

This study brings to spotlight a high prevalence of pterygium of $12.8 \%$ among adults aged 18 years and above presenting to the ophthalmology OPD. The highest prevalence of pterygium was noted in those aged 36-55 years. The risk factors associated with pterygium include age more than 35 years and outdoor occupation. Use of sunglasses may have a protective effect against pterygium.

\section{ACKNOWLEDGEMENTS}

Special thanks to Dr. Sithar Dorji and Mr. Indra Prasad Sharma for their technical advice. We also would like to thank all the staff of the Department of Ophthalmology for their unwavering support in the conduct of this study.

\section{REFERENCES}

1. Bowling B. Kanski's Clinical Ophthalmology. $8^{\text {th }}$ Ed. Elsevier. 2016; 162p. [Full Text]

2. Alqahtani JM. The prevalence of pterygium in Alkhobar: a hospital-based study. J Family Community Med. 2013; 20(3):159-61. [PubMed | Full Text | DOI]

3. Shrestha S, Shrestha SM. Comparative study of prevalence of pterygium at high altitude and Katmandu valley. J Nepal Health Res Counc. 2014; 12(28):187-90. [Full Text | DOI]

4. Liu L, Wu J, Geng J, Yuan Z, Huang D. Geographical prevalence and risk factors for pterygium: a systematic review and meta-analysis. BMJ Open. 2013; 3:e003787. [Full Text | DOI]

5. Nangia V, Jonas JB, Nair D, Saini N, Nangia P, Jonas SP. Prevalence and associated factors for pterygium in rural agrarian central India: The Central India Eye and Medical Study. PLoS One. 2013; 8(12):e82439. [Full Text | DOI]

6. Anbesse DH, Kassa T, Kefyalew B, Tasew A, Atnie A, Desta $\mathrm{B}$, et al. Prevalence and associated factors of pterygium among adults living in Gondar city, Northwest Ethiopia. PLoS One. 2017;12(3):e0174450. [Full Text | DOI] 
7. Hashemi H, Khabazkhoob M, Yekta A, Jafarzadehpour E, Ostadimoghaddam H, Kangari $H$. The prevalence and determinants of pterygium in rural areas. J Curr Ophthalmol. 2016; 1-5. [Full Text | DOI]

8. Moran DJ, Hollows FC. Pterygium and ultraviolet radiation: a positive correlation. Br J Ophthalmol.1984; 68:343-6. [Full Text | DOI]

9. Kwok LS, Coroneo MT. A model for pterygium formation. Cornea. 1994; 13(3):219-24. [Full Text | DOI]

10. Maharjan IM, Shresth E, Gurung B, Karmacharya S. Prevalence of and associated risk factors for pterygium in the high-altitude communities of Upper Mustang, Nepal. Nepal J Ophthalmol. 2014; 6(11):65-70. [Full Text | DOI]

11. Panchapakesan J, Hourihan F, Mitchell P. The prevalence of pterygium and pinguecula: The blue mountains eye study. Aust N Z J Ophthalmol. 1998; 26 Suppl 1:S2-5. [Full Text | DOI]

12. Marmamula S, Khanna RC, Rao GN. Population - based assessment of prevalence and risk factors for pterygium in the South Indian state of Andhra Pradesh: The Andhra Pradesh Eye Disease Study. Invest Ophthalmol Vis Sci. 2013; 54(8):5360. [Full Text | DOI]

13. Drvmvrvprasadarao M.S. Effects of pterygium on tear film. IOSR-JDMS. 2017; 16(3):61-3.

14. Shelke E, Kawalkar U, Wankar R, Nandedkar V, Khaire $\mathrm{B}$, Gosavi V. Effect of pterygium excision on pterygium induced astigmatism and visual acuity. Int J Adv Health Sci. 2014; 1(8). [Full Text]

15. Zare M, Zarei-Ghanavati S, Ansari-Astaneh M, BaradaranRafiee A, Einolahi B. Effects of pterygium on ocular aberrations. Cornea. 2010 Nov; 29 :1232-5. [Full Text | DOI]
16. Petry NM. A comparison of young, middle-aged, and older adult treatment-seeking pathological gamblers. Gerontologist. 2002 Feb;42(1):92-9. [Full Text | DOI]

17. Kalanchiarani S, Kannan V, Ghouse NF. A study on corneal astigmatism in pterygium cases before and after surgery. JEBMH. 2018 Feb;5:830-5. [Full Text | DOI]

18. McCarty CA, Fu CL, Taylor HR. Epidemiology of pterygium in Victoria, Australia. Br J Ophthalmol. 2000; 84;289-92. [Full Text $\mid$ DOI]

19. Nemesure B, Wu SY, Hennis A, Leske MC. Nine Year incidence and risk factors for pterygium in the Barbados eye studies. Ophthalmology. 2008;115(12):2153-8. [Full Text | DOI]

20. Ukponmwan CU, Dawudo OA, Edema OF, Okojie O. Prevalence of pterygium and pinguecula among motorcyclist in Nigeria. East African Medical Journal. 2007; 84(11):51621. [Full Text]

21. Lu P, Chen X, Kang Y, Ke L, Wei X, Zhang W. Pterygium in Tibetans: a population-based study in China. Clin Exp Ophthalmol. 2007; 35(9):823-33. [Full Text | DOI]

22. Rim TH, Nam J, Kim TI. Risk factors associated with pterygium and its sub- types in Korea: The Korean National Health and Nutrition Examination Survey 2008-2010. Cornea 2013;32:962-70. [Full Text | DOI]

23. Song E, Sun HP, Xu Y, pan CW. Cigarette smoking and pterygium: A propensity score matching analysis. Optom Vis Sci. 2016;93:466-70. [Full Text | DOI]

24. Malekifar P, Esfandiari H, Behnaz N, Javadi F, Azish S, Javadi MA, et al. Risk factors for pterygium in Ilam Province, Iran. J Ophthalmic Vis Res. 2017;12(3):270-4. [PubMed | Full Text | DOI]

\section{AUTHORS CONTRIBUTION}

Following authors have made substantial contributions to the manuscript as under:

CW: Concept, analysis of data, study design, manuscript drafting and critical reviews

NTL: Concept, analysis of data, study design, manuscript drafting and critical reviews

Authors agree to be accountable for all respects of the work in ensuring that questions related to the accuracy and integrity of any part of the work are appropriately investigated and resolved.

\section{CONFLICT OF INTEREST \\ None}

\section{GRANT SUPPORT AND FINANCIAL DISCLOSURE}

Ministry of Health, Royal Government of Bhutanr 